\title{
Toughness improvement of epoxy composites using a kind of environment-friendly bio-based polyester polyol
}

\section{Xinyu Shang}

Northeast Forestry University

Lei Xue

Northeast Forestry University

Yanhua Zhang ( $\nabla$ zhangyanhua@nefu.edu.cn)

Key Laboratory of Bio-Based Material Science and Technology, Northeast Forestry University, Ministry of Education https://orcid.org/0000-0003-4265-1090

\section{Research Article}

Keywords: Lignin, Polyester polyol, Epoxy resin, Toughening, Composite

Posted Date: January 28th, 2022

DOI: https://doi.org/10.21203/rs.3.rs-1283418/v1

License: (9) This work is licensed under a Creative Commons Attribution 4.0 International License. Read Full License 


\section{Abstract}

Epoxy resin (EP) is a thermosetting resin with prominent performances and wide applications. However, the inherent brittleness limits its development in the engineering materials area. A liquid bio-based polyester polyol (LLP) with flexible long chains was synthesized in this study by melt polycondensation of corn straw lignin. After being compounded with EP (LLP/EP), the mechanical property, micromorphology and thermal behavior of the composite were evaluated. The experimental result indicated that the fracture brittleness of EP composite was decreased by importing the LLP. The bending and impact strength were up to $113.67 \mathrm{MPa}$ and $51.29 \mathrm{~kJ} / \mathrm{m}^{2}$ for $10 \%$-LLP/EP, which were $5.25 \%$ and $27 \%$ higher than those of unmodified EP. The results of this work build new avenues for the efficient utilization of lignin and the development of low-cost, high-performance and well environmentally adaptable EP composite by renewable resources.

\section{Introduction}

Epoxy resin (EP) has been widely used in coatings, adhesives, and electronics because of its good adhesive strength, superior insulation, and excellent chemical corrosion resistance. However, the fragility of the cured product is strong, which greatly limits the application in engineering materials [1-3]. Therefore, the toughening modification of EP has become the hotspot of the current research.

Due to the superiorities of high reactivity and being renewable, lignin is considered to have enormous potential in material modification and thus has attracted particular attention [4]. However, lignin as a powder modifier can easily agglomerate in the matrix resin resulting in poor interfacial adhesion. To solve the above problems, an overwhelming number of studies have focused on the chemical modification of lignin to toughen epoxy resin [5-10].

This study designed and synthesized a novel liquid bio-based polyester polyol (LLP) with flexible long chains by corn straw lignin using a very simple one-step method. Different from the previous ways [1113], LLP derived from biomass resources is low-cost, simple to prepare and easier compatible with resin. Consequently, this toughening strategy gave EP composites a bright future in the development of casting or potting materials.

\section{Materials And Methods}

\subsection{Materials}

Corn straw lignin with an average particle size of $11 \mu \mathrm{m}$, a purity of $94.8 \%$, and a phenolic hydroxyl content of $12.9 \%$ was provided by Longli Biotechnology Co., Ltd. (Shandong, China). The lignin was kept in a vacuum oven at $60^{\circ} \mathrm{C}$ for three days to remove the moisture before using it. Epoxy resin (E-54) was bought from Nantong Xingchen Synthetic Materials Co., Ltd. (Jiangsu, China). A low-molecular-weight polyamine curing agent (TY-200) was purchased from Yanhai Chemical Co., Ltd. (Tianjin, China), and its 
amine value was 230 260 mgKOH/g. Ethylene glycol, neopentyl glycol, and sebacic acid were supplied by Sinopharm-Group Chemical Reagent Co., Ltd. (China). Antimony trioxide $\left(\mathrm{Sb}_{2} \mathrm{O}_{3}\right)$ was purchased from Zhanyun Chemical Co., Ltd (Shanghai, China).

\subsection{Synthesis of LLP}

LLP was obtained by esterification reaction of diols, diacids and triols completely were substituted for the lignin. The specific process was carried out as follows. The raw materials were placed in a four-port flask and heated to completely melt by an electric heating sleeve. At pre-polycondensation, the system was heated to $140{ }^{\circ} \mathrm{C}$ for 1 hour. Then, segmented polymerization occurred from $150{ }^{\circ} \mathrm{C}$ to $250{ }^{\circ} \mathrm{C}$ for 5 hours. In the post-polycondensation stage, the temperature of the system was reduced to $100{ }^{\circ} \mathrm{C}$, and the reaction continued for 2 hours in the presence of the $\mathrm{Sb}_{2} \mathrm{O}_{3}$ catalyst to increase the reaction rate $[14,15]$. The whole polymerization needed to be carried out under reduced pressure (vacuum gradually increased to $0.08 \mathrm{Mpa}$ ) and nitrogen protection in order to avoid the material being subjected to long periods of high-temperature oxidation and get rid of by-products in time.

\subsection{Preparation of LLP/EP composites}

The E-54, TY-200, and the dehydrated LLP were blended (E-54: TY-200=1:1 wt\%) and stirred evenly with a glass rod, and rotated in a vacuum defoamer for 5 minutes to remove bubbles. The viscous mixture was slowly cast into the polytetrafluoroethylene (PTFE) mold and then placed in an oven, cured under a curing condition of $50^{\circ} \mathrm{C} / 3 \mathrm{~h}+120^{\circ} \mathrm{C} / 2 \mathrm{~h}$, as shown in Scheme 1 . As the addition of LLP increased from $0-5 \%$, $10 \%, 15 \%$ and $20 \%$, the epoxy resin composites toughened by LLP were named 0\%-LLP/EP, $5 \%$-LLP/EP, 10\%-LLP/EP, 15\%-LLP/EP, and 20\%-LLP/EP, respectively.

\subsection{Characterizations}

Measurement of LLP and EP composites are detailed in Supplementary Material.

\section{Results And Discussion}

\subsection{Characterization of LLP}

Compared with the original lignin, the hydroxyl characteristic peak at $3450 \mathrm{~cm}^{-1}$ and the conjugated carbonyl peak at $1650 \mathrm{~cm}^{-1}$ disappeared, while the ester characteristic peak of LLP appeared at $1732 \mathrm{~cm}^{-1}$. It can be seen from Fig. 1 that lignin participates in the polycondensation reaction as an alcohol compound.

Various parameters of the LLP are listed in Table1. The low viscosity LLP prepared in this experiment will not cause the viscosity of the system to increase sharply. It is convenient for the subsequent experimental manipulation. Both acid value and hydroxyl value are in a suitable range, which will make a good interaction between LLP and matrix resin. 
Table 1

General properties of LLP

\begin{tabular}{|c|c|c|c|}
\hline Sample & Viscosity at $25^{\circ} \mathrm{C}(\mathrm{mPa} \cdot \mathrm{s})$ & Hydroxyl Value (mg/g) & Acid Value (mg/g) \\
\hline LLP & $22.7 \sim 23.4$ & $142 \sim 145$ & $0.25 \sim 0.4$ \\
\hline
\end{tabular}

The bending strength of the cured EP with different amounts of LLP is shown in Fig. 2(a). The maximum value of ca.114 Mpa was obtained when the LLP amounted to $10 \%$. Compared with pristine EP, it increased by ca. $5.25 \%$. With the persistent addition of LLP, the bending property of composites decreased slightly after reaching the peak but still maintained close to the original level. This result shows when LLP accounts for a low proportion in the epoxy resin system (the mass fraction is less than $15 \%$ ), the flexible segment in its structure does not reduce the yield deformation ability of cured epoxy resin. Regarding the improvement of bending strength, it is believed that the alcohol hydroxyl groups contained in the LLP participate in the curing reaction of epoxy resin, which promotes the deepening of crosslinking degree. On the other hand, hydroxyl groups that do not involve in the reaction may also form intermolecular or intramolecular hydrogen bonds. They can absorb more energy during deformation, thus further improving their bending resistance. The impact strength of the epoxy resin is an important index to determine its toughness. As can be seen from Fig. 2(b), in contrast to the unmodified epoxy resin $\left(40.34 \mathrm{~kJ} / \mathrm{m}^{2}\right)$, the impact strength of the cured epoxy resin modified by LLP could be significantly improved. The maximum impact strength reached $51.29 \mathrm{~kJ} / \mathrm{m}^{2}$ which got an increase of about $27 \%$. It means that the addition of an appropriate amount of liquid polyester polyol can play an important role in toughening the matrix resin. Since the LLP can be well dissolved in the epoxy resin, the flexible chains in its structure increase the free volume in the three-dimensional network. When the resin was impacted by an external force, the movement of the molecular chain was easier.

\subsection{Micromorphology}

Figure 2(c) showed the fractural cross-sectional SEM images of 0\%-LLP/EP, $10 \%$-LLP/EP and 20\%LLP/EP, respectively. When the amount of LLP was no more than $10 \%$, its impact cross-section merely showed sparse wrinkles. It could also be seen from the figure of $10 \%$-LLP/EP that a large number of crazing areas and sidestep-like gullies occurred inside the EP. The toughening mechanism of LLP can be fully explained according to the theory of craze and shear ribbon proposed by Bucknall et al [16]. In our system, LLP acted as the core of stress concentration to induce plenty of crazes and shear ribbons. Besides, the flexible long chain of LLP could control the development of crazes and stop them from changing into destructive cracks. The stress field at the tip of the striation induced the generation of a shear band, and the shear ribbon also prevented the further development of the striation. The generation

and spread of crazes or shear ribbons are needed to consume a large amount of energy, thus significantly improving the impact strength of materials. As the LLP continued to add, the microphase separation structure or even over-plasticizing phenomenon appeared in the composite materials. At this point, the 
impact strength of the composites tended to decrease, which was consistent with the above mechanical analysis.

\subsection{Thermal analysis of EP composites}

Figure 3(a), 3(b) showed the curves of storage modulus and loss factor with temperature obtained by DMA analysis to characterize the viscoelasticity and glass transition temperature $\left(T_{g}\right)$ range of LLP/EP composites. In Figure 3(a), the storage modulus of LLP/EP composites was higher than that of pure epoxy resin. All the curves in Figure 3(b) were unimodal, indicating that LLP had good compatibility with matrix resin. With the increase of LLP addition, the maximum value of $\tan \delta$ moved to the lowtemperature region in a small range. As shown in Figure 3(c) and 3(d), a significant thermal decomposition hysteresis was observed by the TGA test. It indicated that the thermal stability of EP composites toughened by LLP was well maintained. This was all attributed to the special chemical structure of lignin. Based on the above analysis, the comprehensive analysis showed that the EP composites exhibited optimal performance in all aspects when the amount of LLP was up to $10 \%$.

\section{Conclusions}

In this work, we corroborated the approach of epoxy resin composites with advantageous toughness by using liquid lignin-based polyester polyol (LLP) with flexible long chains as the toughening agent. SEM images confirmed that the fracture cross-section of 10\%-LLP/EP composite was rough, then craze and shear ribbon was obvious. The mechanical test results suggested that the impact strength of the epoxy resin composite with $10 \mathrm{wt} \%$ LLP was $27 \%$ higher than the untoughened epoxy resin. Also, its bending strength was increased by about $5 \mathrm{MPa}$. Furthermore, the DMA results indicated that the thermal properties of LLP/EP composites did not decrease significantly when the addition of LLP was $10 w t \%$. This paper provides a novel idea for the utilization of corn straw lignin, in which the epoxy resin composite presented outstanding performances at a lower cost.

\section{CRediT authorship contribution statement}

Xinyu Shang applies oneself to writing-original drafts. Lei Xue applies oneself to the investigation. Yanhua Zhang applies oneself to the conceptualization and writing-review \& editing.

\section{Declarations}

The authors declare that they have no known competing financial interests or personal relationships that could have appeared to influence the work reported in this paper.

\section{Acknowledgments}


This work was supported by the Foundation of "Special Project for Double First-Class-Cultivation of Innovative Talents" from Northeast Forestry University [No. 000/41113102] and the Fundamental Research Funds for the Central Universities [No. 2572019CG05]. Special thanks for the support of the Chinese University Students' Innovation and Entrepreneurship Project [No. CL202110].

\section{References}

1. Zhang YT, Pang H, Wei DD et al (2019) Preparation and characterization of chemical grouting derived from lignin epoxy resin. Eur Polym J. https://doi.org/10.1016/j.eurpolymj.2019.05.003

2. Zhan ZS, Zhang YL, Zhang Y (2019) Improving the flame retardancy and electrical conductivity of epoxy resin composites by multifunctional phosphorus-containing polyaniline. Mater Lett. https://doi.org/10.1016/j.matlet.2019.127092

3. Zhang JH, Chen SY, Qin B et al (2019) Preparation of hyperbranched polymeric ionic liquids for epoxy resin with simultaneous improvement of strength and toughness. Polymer. https://doi.org/10.1016/j.polymer.2019.01.003

4. Wang F, Kuai JT, Pan HS et al (2018) Study on the demethylation of enzymatic hydrolysis lignin and the properties of lignin-epoxy resin blends. Wood Sci Technol. https://doi.org/10.1007/s00226-0181024-z

5. Liu WS, Zhou R, Goh HL et al (2014) From Waste to Functional Additive: Toughening Epoxy Resin with Lignin. ACS Appl Mater Inter. https://doi.org/10.1021/am500642n

6. Ferdosian F, Zhang YS, Yuan ZS et al (2016) Curing kinetics and mechanical properties of bio-based epoxy composites comprising lignin-based epoxy resins. Eur Polym J.

https://doi.org/10.1016/j.eurpolymj.2016.07.014

7. Jablonskis A, Arshanitsa A, Arnautov A et al (2018) Evaluation of Ligno Boost (TM) softwood kraft lignin epoxidation as an approach for its application in cured epoxy resins. Ind Crops Prod. https://doi.org/10.1016/j.indcrop.2017.12.003

8. Feghali E, van de Pas J, Parrott D AJ, et al (2020) Biobased Epoxy Thermoset Polymers from Depolymerized Native Hardwood Lignin. ACS Macro Lett. https://dx.doi.org/10.1021/acsmacrolett.0c00424

9. Guo XJ, Xin JN, Huang JJ et al (2019) Preparation and toughening of mechanochemically modified lignin-based epoxy. Polymer. https://doi.org/10.1016/j.polymer.2019.121859

10. Feng LB, He X, Zhang YP et al (2021) Triple Roles of Thermoplastic Polyurethane in Toughening, Accelerating and Enhancing Self-healing Performance of Thermo-reversible Epoxy Resins. J Polym Environ. https://doi.org/10.1007/s10924-020-01923-4

11. Tsang WL, Taylor AC (2019) Fracture and toughening mechanisms of silica- and core-shell rubbertoughened epoxy at ambient and low temperature. J Mater Sci. https://doi.org/10.1007/s10853-01903893-y 
12. Filippo MD, Alessi S, Palmese G et al (2020) Electrospun rubber/thermoplastic hybrid nanofibers for localized toughening effects in epoxy resins. J Appl Polym Sci. https://doi.org/10.1002/app.48501

13. Hu K, Bao LX, Chen XF et al (2018) Synthesis of Castor Oil-Derived Decanediamide as a Novel Flexible Asphalt-Modified Epoxy Resin Curing Agent. Adv Polym Tech. https://doi.org/10.1002/adv.21760

14. Sun N, Lai YY, Xu YS et al (2020) Preparations and properties of polyurethane adhesives modified by corn straw lignin. BioRes. https://doi.org/10.15376/biores.15.2.3970-3983

15. Sun N, Di MW, Liu Y (2021) Lignin-containing polyurethane elastomers with enhanced mechanical properties via hydrogen bond interactions. Int J Biol Macromol.

https://doi.org/10.1016/j.jibiomac.2021.06.038

16. Bucknall CB, Smith RR (1965) Stress-Whitening in High-Impact Polystyrenes. Polymer. https://doi.org/10.1016/0032-3861(65)90028-5

\section{Scheme 1}

Scheme 1 is available in Supplemental Files section.

\section{Figures}




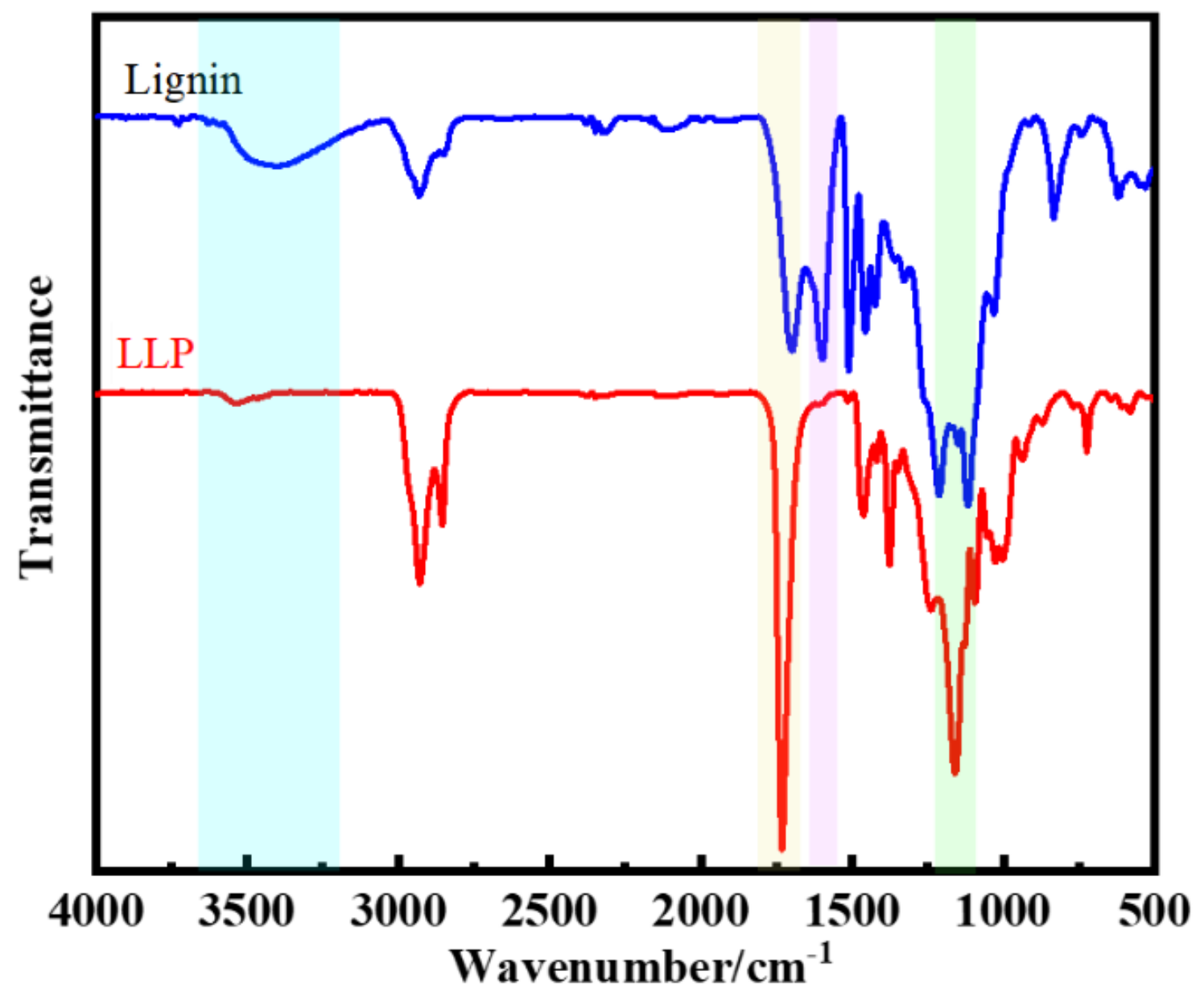

Figure 1

FTIR spectra of Lignin and LLP

Figure 2

(a) the bending strength; (b) the impact strength; (c)SEM images of different LLP/EP

Figure 3 
(a) the storage modulus; (b) tan $\delta$; (c) TGA of different LLP/EP; (d) partial enlarged of (c)

\section{Supplementary Files}

This is a list of supplementary files associated with this preprint. Click to download.

- Supplement.docx

- Graphicabstract.tif.png

- Scheme1.tif.png 